\title{
Article \\ Thixotropic Hydrogels Composed of Self-Assembled Nanofibers of Double-Hydrophobic Elastin-Like Block Polypeptides
}

\author{
Yusuke Sugioka $^{1}$, Jin Nakamura ${ }^{1}\left(\mathbb{D}\right.$, Chikara Ohtsuki $^{1}{ }^{1}$ and Ayae Sugawara-Narutaki ${ }^{2, *(\mathbb{D}}$ \\ 1 Department of Materials Chemistry, Graduate School of Engineering, Nagoya University, Furo-cho, \\ Chikusa-ku, Nagoya 464-8603, Japan; yusuke.s.es@gmail.com (Y.S.); \\ nakamura@chembio.nagoya-u.ac.jp (J.N.); ohtsuki@chembio.nagoya-u.ac.jp (C.O.) \\ 2 Department of Energy Engineering, Graduate School of Engineering, Nagoya University, Furo-cho, \\ Chikusa-ku, Nagoya 464-8603, Japan \\ * Correspondence: ayae@energy.nagoya-u.ac.jp; Tel.: +81-52-789-3602
}

Citation: Sugioka, Y.; Nakamura, J.; Ohtsuki, C.; Sugawara-Narutaki, A. Thixotropic Hydrogels Composed of Self-Assembled Nanofibers of Double-Hydrophobic Elastin-Like Block Polypeptides. Int. J. Mol. Sci. 2021, 22, 4104. https://doi.org/ $10.3390 /$ ijms22084104

Academic Editor: Kazunori Matsuura

Received: 30 March 2021

Accepted: 12 April 2021

Published: 15 April 2021

Publisher's Note: MDPI stays neutral with regard to jurisdictional claims in published maps and institutional affiliations.

Copyright: (c) 2021 by the authors. Licensee MDPI, Basel, Switzerland. This article is an open access article distributed under the terms and conditions of the Creative Commons Attribution (CC BY) license (https:// creativecommons.org/licenses/by/ $4.0 /)$.

\begin{abstract}
Physically crosslinked hydrogels with thixotropic properties attract considerable attention in the biomedical research field because their self-healing nature is useful in cell encapsulation, as injectable gels, and as bioinks for three-dimensional (3D) bioprinting. Here, we report the formation of thixotropic hydrogels containing nanofibers of double-hydrophobic elastin-like polypeptides (ELPs). The hydrogels are obtained with the double-hydrophobic ELPs at $0.5 \mathrm{wt} \%$, the concentration of which is an order of magnitude lower than those for previously reported ELP hydrogels. Although the kinetics of hydrogel formation is slower for the double-hydrophobic ELP with a cell-binding sequence, the storage moduli $G^{\prime}$ of mature hydrogels are similar regardless of the presence of a cell-binding sequence. Reversible gel-sol transitions are demonstrated in step-strain rheological measurements. The degree of recovery of the storage modulus $\mathrm{G}^{\prime}$ after the removal of high shear stress is improved by chemical crosslinking of nanofibers when intermolecular crosslinking is successful. This work would provide deeper insight into the structure-property relationships of the self-assembling polypeptides and a better design strategy for hydrogels with desired viscoelastic properties.
\end{abstract}

Keywords: elastin-like polypeptide; physical hydrogel; thixotropic gel; self-healing; chemical crosslinking

\section{Introduction}

Hydrogels have attracted great attention as three-dimensional (3D) cell culture scaffolds since they act like an in vivo microenvironment around cells [1-3]. It is important to design hydrogels with proper physicochemical and mechanical properties, especially in tissue regeneration and tissue model construction because cellular behaviors are siginificantly affected by those properties. In these contexts, biomimicry of the natural extracellular matrix (ECM) is a rational approach to constructing successful hydrogels for tissue regeneration.

The principal component of ECM is collagen, and its extraction, purification, and processing from animals have been established. Various types of collagen gels are available, and they are widely used in tissue regeneration. Elastin is another essential ECM protein in soft tissues, such as blood vessels, lungs, ligaments, and skin [4]. The mechanical properties of these tissues are controlled by a combination of collagen and elastin. Collagen provides tensile strength, while elastin provides extensibility and reversible recoil [5]. Unlike collagen, however, the use of naturally occurring elastin as cell culture scaffolds is underexplored because of the difficulty of purifying and processing elastin, caused by its intrinsic insolubility.

Researchers have attempted to develop elastin-like hydrogels using the biomimicry approach [6,7]. Chemically crosslinked, cell-compatible elastin-like hydrogels have been constructed carefully designing the crosslinking reactions. Weiss et al. synthesized methacry- 
late derivative of tropoelastin, the monomeric form of elastin [8,9]. This derivative is photo-crosslinked to form hydrogels within a minute upon ultraviolet (UV) irradiation. Because the period of UV irradiation is short enough, the process is compatible with cell encapsulation. Elastin-like polypeptides (ELPs) are a class of polypeptides that consists of repetitive amino acid motifs of natural elastin [10]. Typical ELPs consist of repeats of Val-Pro-Gly-Xaa-Gly (VPGXG), where Xaa is a guest amino acid residue, except for Pro. By incorporating Lys or Gln residue at the Xaa position, chemical modification of the ELP is possible. For example, McHale et al. used the enzyme transglutaminase to couple between Lys and Gln side chains in ELPs under mild conditions [11]. Chondrocytes were cultured for more than four weeks in the resultant hydrogel. Cell-compatible ELP hydrogels have also been obtained using click chemistry reactions $[12,13]$. The Lys residues of one ELP were modified with azide groups while those in the other ELP were functionalized with cyclooctyne groups. Catalyst-free click reactions occured on mixing these ELPs, yielding a hydrogel. The click hydrogels, with cell-adhesive and biodegradable properties, were successful in tissue regeneration, in animal models of volumetric muscle loss [14], myocardial infarction [15], and critical limb ischemia [16].

One of the characteristics of ELPs is the temperature-responsive self-aggregation properties. ELPs are soluble in cold water but become insoluble and coacervate above their transition temperature $\left(T_{\mathrm{t}}\right)$, which can be controlled by adjusting the guest residue composition, molecular weight, and concentration of ELP $[10,17]$. Physically crosslinked ELP hydrogels, where the driving force of crosslinking is hydrophobic interactions, have been constructed by taking advantage of these temperature-responsive properties. While typical ELPs with XPGVG repeat sequence phase-separate from the solution above their $T_{\mathrm{t}}$, the substitution of the third Gly with Ala in the pentapeptide results in the formation of a hydrogel as a continuous phase [18]. This substitution slowed the ELPs' dynamics above $T_{\mathrm{t}}$, enabling the formation of kinetically arrested and phase-separated nanostructures. Physically crosslinked hydrogels were also formed from the modular ELP consisting of alternating (VPGXG) ${ }_{n}$ and polyalanine helix domains [19,20], amphiphilic ELP block copolymers with different temperature responses between the two blocks [21,22]. ELP motifs serve as a temperature-responsive building unit of fusion proteins. ELPs were combined with other self-assembling peptide units such as coiled-coil $[23,24]$ and silklike motifs [25-27] to give hydrogels formed by dual self-assembling mechanisms. These physically crosslinked hydrogels often have nonlinear viscoelastic properties, which are useful in cell encapsulation, hydrogel injection, and 3D bioprinting [28].

We have reported that double-hydrophobic ELP block copolymers with (VGGVG) $5_{5}$ $\left(\right.$ VPGXG) ${ }_{n}-(\text { VGGVG) })_{5}(n=25$ or 50$)$ sequences self-assembled to form well-defined nanofibers in aqueous solution $[29,30]$. Dynamic rheology measurements revealed that nanofiber dispersion, even at extremely low nanofiber concentration $(0.034 \mathrm{wt} \%)$, exhibited solid-like behavior with storage modulus $\mathrm{G}^{\prime}$ greater than the loss modulus $\mathrm{G}^{\prime \prime}$ over a wide range of angular frequencies [30]. This gel-like behavior is attributed to the formation of high-aspect-ratio $(>500)$ nanofibers, through which percolated networks are formed in the solution. However, the gel fell under gravity and was not self-supportive. The objective of this research was to construct self-supporting hydrogels using double-hydrophobic ELPs at higher concentrations and to determine their rheological properties. We found that these ELPs, with or without a cell-binding sequence, can form self-supporting hydrogels in microtubes at $0.5 \mathrm{wt} \%$ polypeptide concentration. This concentration is an order of magnitude lower than those for previously reported ELP hydrogels (typically $>5 \mathrm{wt} \%$ ). Thixotropicity was revealed for the present hydrogels and the degree of self-recovery improved after chemical crosslinking of the nanofibers when intermolecular crosslinking was successful. 


\section{Results}

\subsection{Formation of Hydrogels}

In this study, we used double-hydrophobic ELPs, GPG1 and GPG3 to obtain hydrogels (Figure 1). GPG1 and GPG3 contain a common self-assembling sequence (VGGVG) $5^{-}$ (VPGXG) $)_{25}-(\mathrm{VGGVG})_{5}$, where $\mathrm{X}$ is V $(80 \%)$ or $\mathrm{F}(20 \%)$ (F: Phe) to tune the $T_{\mathrm{t}}$ around room temperature [31]. The VPGXG motif in the central block and the VGGVG motif in the end blocks are derived from those in tropoelastin's proline-rich and glycine-rich hydrophobic domains, respectively [32]. Only GPG3 has an additional KAAKGRGDS sequence (K: Lys, A: Ala, R: Arg, D: Asp, and S: Ser) at the C-terminus, in which KAAK is a motif from crosslinking domain of tropoelastin, and GRGDS is a cell-binding motif of fibronectin.

(a)

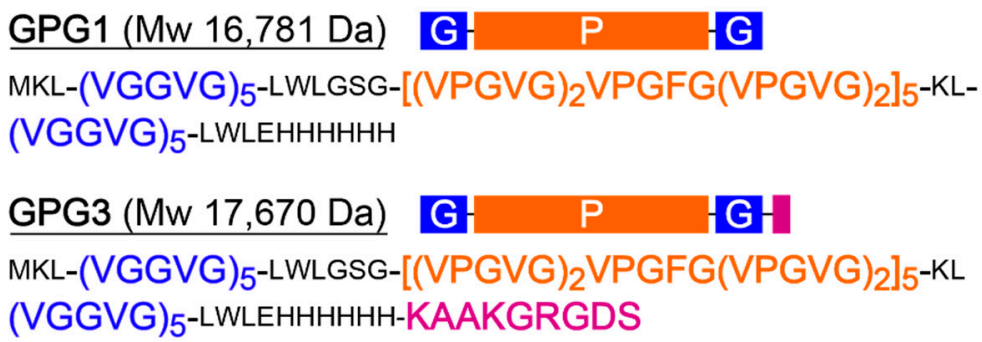

(b)

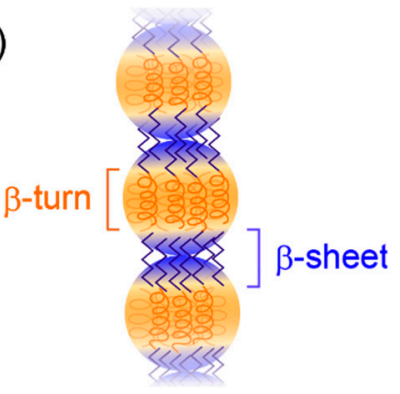

Figure 1. (a) Amino acid sequences of GPG1 and GPG3. (b) Plausible structural model for nanofibers of GPGs.

The mechanisms of nanofiber formation of GPGs have been proposed as follows [29,30,33]. They consist of a two-step pathway: (1) GPGs hydrophobically assemble to form nanoparticles rich in $\beta$-turn structures through dehydration of the (VPGXG) $)_{25}$ block, and (2) the nanoparticles connect into nanofibers along with the formation of $\beta$-sheet structures between the nanoparticles via (VGGVG) 5 blocks (Figure 1b) $[29,30,33]$.

GPG1 and GPG3 were each dissolved at $0.5 \mathrm{wt} \%$ in $10 \mathrm{w} / \mathrm{v} \%$ sucrose aqueous solution followed by heating at $37^{\circ} \mathrm{C}$. The formation of self-supporting hydrogels in microtubes was confirmed after one day $(1 \mathrm{~d})$ for the sample containing GPG1 (Figure 2a inset). The sample that contains GPG3 remains fluidic after $1 \mathrm{~d}$ but lost the fluidity after $7 \mathrm{~d}$ (Figure $2 \mathrm{~b}$ inset). These hydrogels were optically clear. Transmission electron microscopy (TEM) observation revealed the formation of nanofibers in these hydrogels (Figure 2a,b). The nanofibers are relatively straight with diameters of less than $10 \mathrm{~nm}$.
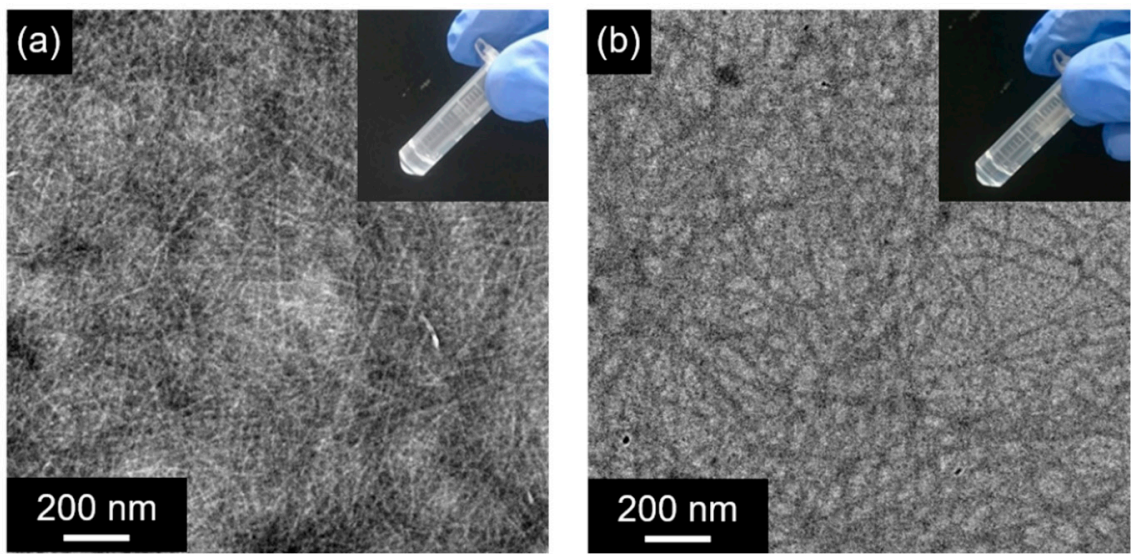

Figure 2. TEM images of the hydrogel of (a) $0.5 \mathrm{wt} \%$ GPG1, $1 \mathrm{~d}$ at $37^{\circ} \mathrm{C},(\mathbf{b}) 0.5 \mathrm{wt} \%$ of GPG3, $7 \mathrm{~d}$ at $37^{\circ} \mathrm{C}$. Insets show photographs of the hydrogels. 


\subsection{Dynamic Rheological Characteristics of Hydrogels}

Dynamic rheological characteristics of the hydrogels are shown in Figure 3. Strain sweep measurements of a GPG1 hydrogel formed after $1 \mathrm{~d}$ at $37^{\circ} \mathrm{C}$ showed that $\mathrm{G}^{\prime}$ and $\mathrm{G}^{\prime \prime}$ were relatively constant between $0.1 \%$ and $1 \%$ strains and both moduli decreased at above $2 \%$ strain (Figure 3a). This indicates a transition from a linear to nonlinear viscoelastic regime. Frequency sweep measurement of GPG1 hydrogel at 1\% strain showed that $\mathrm{G}^{\prime}$ was approximately an order of magnitude higher than $G^{\prime \prime}$ for all ranges of frequencies measured (Figure $3 b$ ). In addition, $G^{\prime}$ and $G^{\prime \prime}$ were constant regardless of the frequency. These characteristics highlight the elastic solid nature of the GPG1 hydrogel. Moduli for GPG3 hydrogels in the strain sweep measurements showed that gels formed after both $1 \mathrm{~d}$ and $7 \mathrm{~d}$ possess elastic properties up to $1 \%$ strain (Figure 3a). However, GPG3 gel at $1 \mathrm{~d}$ exhibited a characteristic trend in which $\mathrm{G}^{\prime \prime}$ first increased and then decreased with increasing strain amplitude. This response is known as weak-strain overshoot [34] and was observed in some polymer solution systems [34,35] and peptide hydrogels [36]. In frequency sweep measurements, an increase in the loss moduli $\mathrm{G}^{\prime \prime}$ at higher frequency was observed for GPG3 gel at $1 \mathrm{~d}$ and $7 \mathrm{~d}$, indicating the contribution of fluid-like property (Figure $3 \mathrm{~b}$ ). The storage modulus $\mathrm{G}^{\prime}$ is related to the stiffness of the viscoelastic material, and the order of $\mathrm{G}^{\prime}$ values here is GPG1 $(1 \mathrm{~d})=$ GPG3 $(7 \mathrm{~d})>\operatorname{GPG} 3(1 \mathrm{~d})$.

(a)

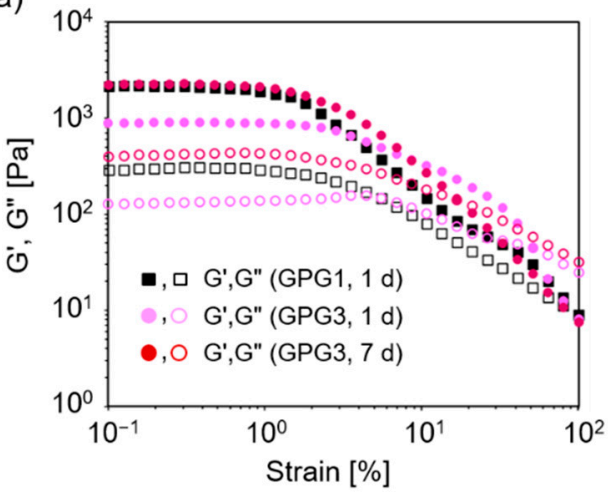

(b)

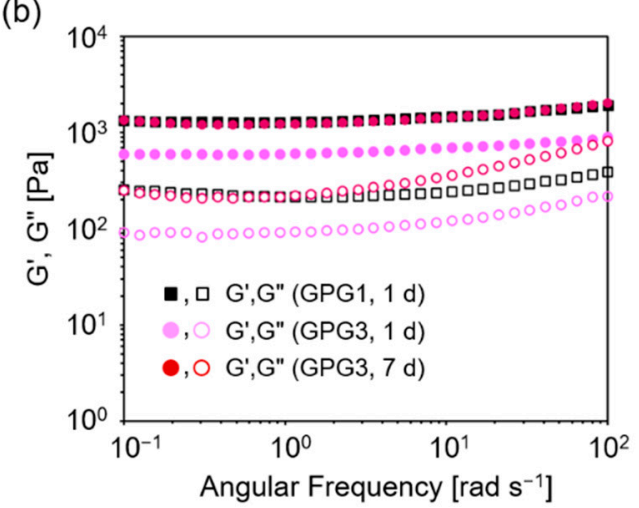

Figure 3. Rheological properties of hydrogels containing GPG1 and GPG3 at $0.5 \mathrm{wt} \%$. (a) Strain sweep $(1 \mathrm{~Hz})$ and $(\mathbf{b})$ frequency sweep ( $1 \%$ strain). The solid and open symbols represent $\mathrm{G}^{\prime}$ and $\mathrm{G}^{\prime \prime}$, respectively.

Figure 4 shows the G' of GPG1 and GPG3 hydrogels at different polypeptide concentrations. There is a power law between the storage modulus and the concentration $\left(\mathrm{G}^{\prime} \sim \mathrm{C}^{n}\right)$ and the exponent $n$ are 1.53 and 1.65 for GPG1 and GPG3 gels, respectively. The $n$ is indicative of the network type [37]. For chemically crosslinked polymer networks, $n$ is around $2.5[38,39]$. Values of $n$ around 1.5 were reported for entangled semiflexible networks such as F-actin [40], unligated fibrin clot [41], filamentous bacteriophage [42], and nanofibers of synthetic peptides $[36,37]$. Therefore, it was suggested that the network structures obtained from GPGs are reminiscent of biological nanofiber systems. 


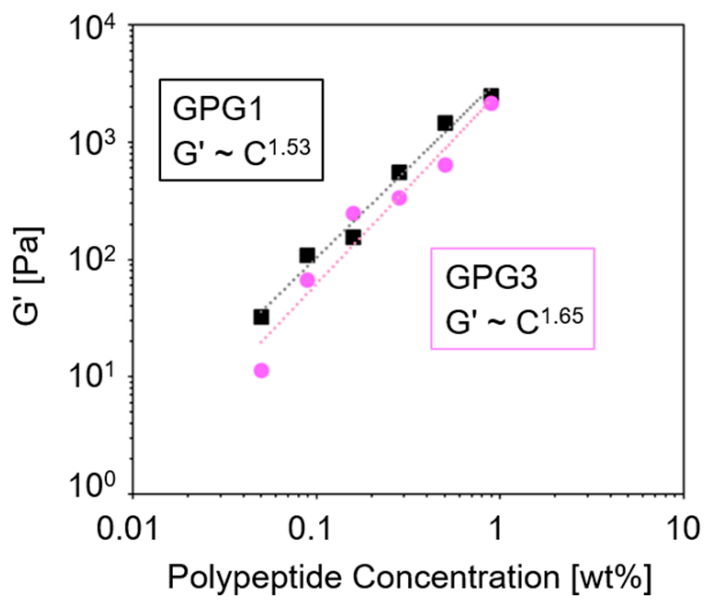

Figure 4. Storage modulus of GPG1 and GPG3 gels with various polypeptide concentrations $(0.050 \mathrm{wt} \%-0.889 \mathrm{wt} \%)$ formed after $1 \mathrm{~d}$ at $37^{\circ} \mathrm{C}$. Time sweep measurements $(1 \mathrm{~Hz}, 1 \%$ strain) were performed for each sample after being transferred to the sample stage, and the $\mathrm{G}^{\prime}$ values at $3600 \mathrm{~s}$ were plotted. The dashed lines represent fits to the data points; the equation of the line for GPG1: $\mathrm{G}^{\prime}=3.48 \times 10^{3} \mathrm{C}^{1.53}, R^{2}=0.984$, and for GPG3: $\left.\mathrm{G}^{\prime}=2.76 \times 10^{3} \mathrm{C}^{1.65}, R^{2}=0.947\right)$.

\subsection{Thixotropicity of Hydrogels}

One of the most interesting properties of the present hydrogels was their thixotropic (i.e., self-healing) nature, where the reversible breaking of the gel under mechanical strain, and the recovery at static conditions took place. The thixotropicity was confirmed with step-strain sweep rheological measurements consisting of the alternating application of high strain $(\gamma=100 \%, 60 \mathrm{~s})$ and low strain $(\gamma=0.5 \%, 600 \mathrm{~s})$ (Figure 5). In both GPG1 and GPG3 gels, $G^{\prime}$ decreased immediately and became smaller than $G^{\prime \prime}$ when the high strain was applied. Upon returning to the low strain, $\mathrm{G}^{\prime}$ increased, and the relationships between $\mathrm{G}^{\prime}$ and $\mathrm{G}^{\prime \prime}$ were reversed. These behaviors indicate the shear-induced, reversible gel-sol transition. Although $\mathrm{G}^{\prime}$ recovered instantaneously when high shear was removed, the following recovery was gradual and $\mathrm{G}^{\prime}$ did not completely recover to the initial values in the period of $600 \mathrm{~s}$. The pattern of recovery was almost the same after the second cycle. The degree of recovery, the $\mathrm{G}^{\prime}$ after third cycles compared with the initial $\mathrm{G}^{\prime}$, was $8 \%$ and $17 \%$ for GPG1 and GPG3 gels, respectively.

(a)

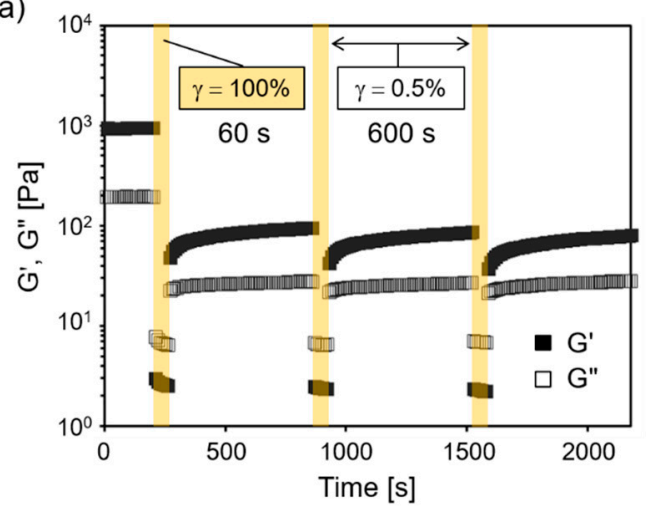

(b)

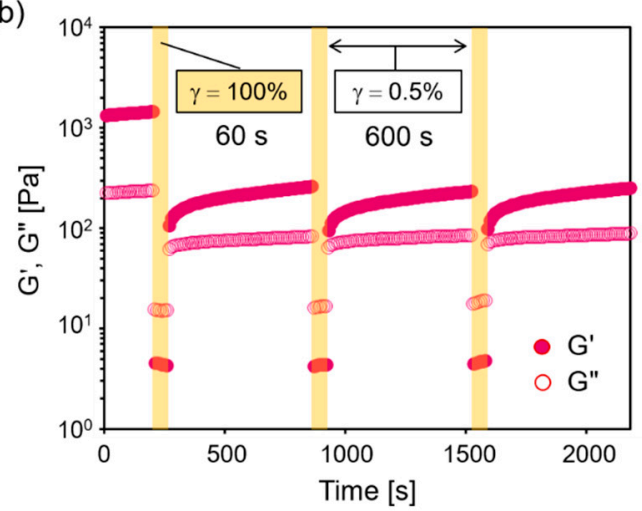

Figure 5. Changes of $\mathrm{G}^{\prime}$ and $\mathrm{G}^{\prime \prime}$ in step-strain sweep dynamic rheological measurements $(1 \mathrm{~Hz})$. (a) $0.5 \mathrm{wt} \%$ GPG1, $1 \mathrm{~d},(\mathbf{b}) 0.5 \mathrm{wt} \%$ GPG3, $7 \mathrm{~d}$. 


\subsection{Effects of Chemical Crosslinks Using Genipin}

We expected that the hydrogels would show improved self-healing ability when GPG nanofibers were chemically crosslinked because the permanent network structure will have resistance to the plastic deformation (Figure 6a). Genipin, a naturally occurring crosslinking agent with low cytotoxicity, was used for this purpose (Figure 6b) [43]. This compound forms chemical crosslinks between primary amino groups. The originally colorless genipin turns blue after the reaction. GPGs have primary amines at $\mathrm{K}$ residues and the N-termini; therefore, the number of the amino groups in GPG1 and GPG3 are three and five, respectively (Figure 1a). Because some reports suggest the dimerization of genipin molecules in the crosslinking reaction [44], the minimum required amount of genipin for complete crosslinking is the same as the number of amino groups in GPG molecules. Therefore, we used 1 and $2 \mathrm{mM}$ genipin solutions, the amounts of genipin molecules which exceed those of amines of GPG1 and GPG3 gels, respectively. As shown in Figure 6c, gels of GPGs turned blue upon the addition of genipin solutions, and the color became stronger in $7 \mathrm{~d}$. To estimate the degree of crosslinking, analysis using sodium dodecyl sulfate-polyacrylamide gel electrophoresis (SDS-PAGE) was performed (Figure 6d). GPG1 nanofibers after genipin treatment and SDS denaturation remained at the well of PAGE gel, indicating the formation of polymerized GPG1 that did not migrate in the PAGE gel. No monomer of GPG1 $(M w=16,781 \mathrm{Da})$ was detectable. On the other hand, there was a band at around $20 \mathrm{kDa}$ for GPG3 besides remaining proteins in the well. This result suggests that the monomer GPG3 $(M w=17,670)$ or those decorated with genipin molecules were still present after genipin treatment.

Dynamic rheological measurements revealed that the range of linear viscoelastic regimes expanded to 3\% strain for GPG1 gel after genipin treatment (Figure 6e). The $\mathrm{G}^{\prime}$ at the plateau region decreased from about 2- to 1-kPa after genipin treatment but still stayed in the same order. Moduli at 100\% strain of genipin-treated gel were smaller than those of untreated gel. Different from GPG1, the linear viscoelastic region as a function of strain was unchanged for GPG3 gel after genipin treatment. However, there was no crossover of $G^{\prime}$ and $G^{\prime \prime}$ after genipin treatment, while $G^{\prime}=G^{\prime \prime}$ at about $20 \%$ strain in unmodified GPG3 gel. This action indicates that GPG3 gel became more solid-like after the crosslinking reaction. The $G^{\prime}$ values at the plateau region became smaller after crosslinking. Step-strain experiments demonstrated that the self-healing property of GPG1 gel improved (Figure 6g) compared to that without crosslinking (Figure 5a). The degree of recovery of $\mathrm{G}^{\prime}$ after the third cycle was $\sim 32 \%$. In contrast, the degree of recovery decreased to 3\% for GPG3 after genipin treatment (Figure $6 \mathrm{~h}$ ). 
(a)

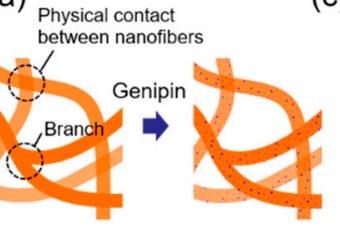

(b)<smiles>COC(=O)C1=COC(O)[C@]2(O)C(CO)=CC[C@H]12</smiles>

(c)

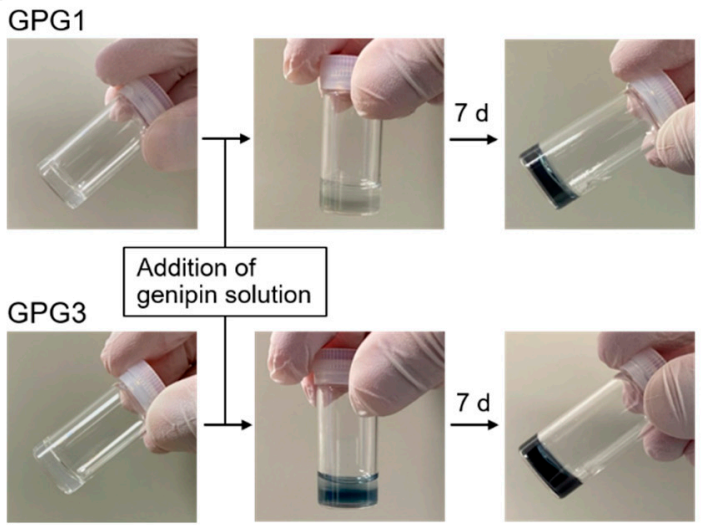

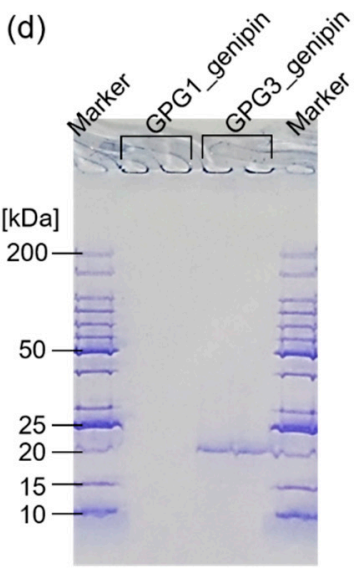

(e)

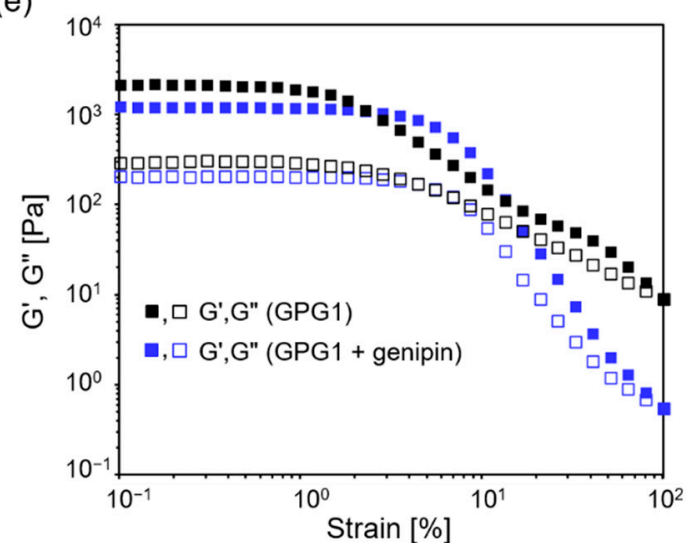

(g)

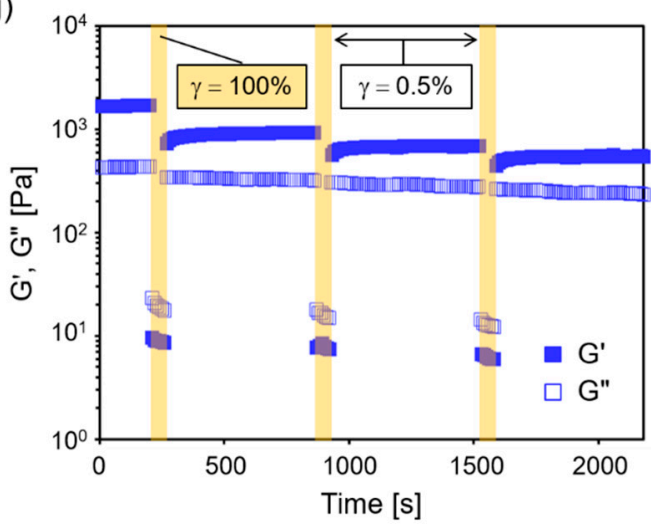

(f)

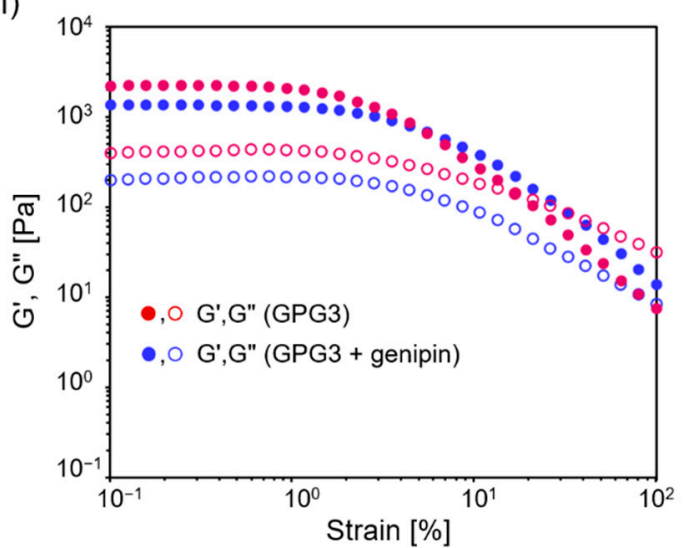

(h)

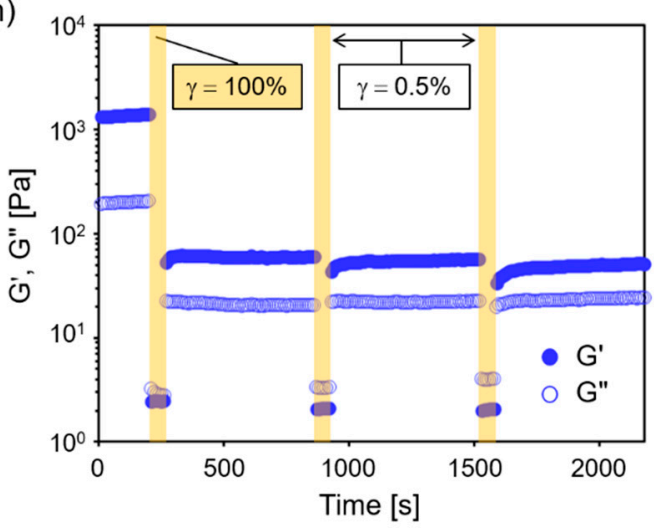

Figure 6. (a) Schematics of the chemical crosslinking of GPG nanofibers. (b) Chemical structure of genipin. (c) Change in the appearance of hydrogels by the addition of genipin solution. The supernatant solutions were removed in the photographs at $7 \mathrm{~d}$. (d) SDS-PAGE of GPG1 and GPG3 gels after reacting with genipin for $7 \mathrm{~d}$. (e,f) Effects of genipin crosslinking on the rheological properties of hydrogels containing (e) GPG1 and (f) GPG3 nanofibers at $0.5 \mathrm{wt} \%$ as a function of strain. The moduli of GPG1 gel at $1 \mathrm{~d}$ and GPG3 gel at $7 \mathrm{~d}$ in Figure 3a are re-plotted as references. (g,h) step-strain sweep measurements of (g) GPG1 and (h) GPG3 gels after genipin treatment.

\section{Discussion}

One of the requirements for hydrogels used in tissue regeneration and tissue model construction is that the biological and mechanical properties are independently controlled to discriminate these effects on tissue regeneration [45]. Therefore, we examined the dynamic viscoelastic properties of hydrogels of GPG1 and GPG3, in which only GPG3 has a cell-binding sequence, to find the condition in which GPG1 and GPG3 gels show similar 
stiffness. In our previous study, fibroblast cells attached and proliferated better on GPG3 nanofibers than on GPG1 nanofibers in 2D cell culture systems [31].

GPG1 $(0.5 \mathrm{wt} \%)$ formed a self-supporting hydrogel in a microtube from $10 \mathrm{w} / \mathrm{v} \%$ sucrose aqueous solution after $1 \mathrm{~d}$ at $37^{\circ} \mathrm{C}$ while it took $7 \mathrm{~d}$ for GPG3, indicating the slower kinetics of nanofiber formation of GPG3 compared to GPG1. The weak-strain overshoot observed in the strain sweep rheological measurement of GPG3 gel at $1 \mathrm{~d}$ indicates that GPG3 is in the process of nanofiber formation, where both monomers and nanofibers of GPG3 are present (Figure 3a). We previously studied the process of nanofiber formation of GPG1 and GPG3 in ultrapure water at more dilute polypeptide conditions $(20 \mu \mathrm{M})$, which correspond to $0.033 \mathrm{wt} \%$ and $0.035 \mathrm{wt} \%$ for GPG1 and GPG3, respectively [31]. Although the polypeptide concentration and solvent were different from this study, the slower assembly of GPG3 was also observed as indicated by the slower formation of $\beta$-sheet structures [31]. Although the difference in amino acid sequences between GPG1 (196 amino acids) and GPG3 (205 amino acids) is less than 5\%, the highly charged KAAKGRGDS additional sequence exerts effects on the self-assembly kinetics probably because it provides electrostatic repulsion between molecules.

Notably, $\mathrm{G}^{\prime}$ values are similar between GPG1 gel formed at $1 \mathrm{~d}$ and GPG3 gel at $7 \mathrm{~d}$ in the frequency sweep dynamic rheological measurements (Figure $3 \mathrm{~b}$ ). This fact shows that these gels have similar stiffness but may have different biological activity, the properties of which are important for future cell study, because one can discuss the effect of only bioactive sequence while keeping the gel stiffness constant. However, we noted that $G^{\prime \prime}$ of GPG3 is more frequency-dependent, showing the contribution of liquid-like property. This phenomenon may be because the nanofiber formation of GPG3 does not reach equilibrium in $7 \mathrm{~d}$.

To the best of our knowledge, this is the first report on the thixotropic behavior of ELP-based hydrogels. Gels containing GPG1 and GPG3 nanofibers immediately become sols on the application of high shear strain. $G^{\prime}$ recovers to $8 \%$ and $17 \%$ of the initial $G^{\prime}$ for GPG1 and GPG3, respectively, after three cycles of high and low strain applications. Although the mechanisms are not fully understood, similar self-healing behavior was observed in other peptide hydrogel systems [46-50]. Wychowaniec et al. pointed out that the recovery of $\mathrm{G}^{\prime}$ consisted of two processes with two characteristic times: a fast recovery process and a slower recovery process. The former process is likely a fast percolation of the globular hydrogel domains, which were clusters of original hydrogel generated under shear [46]. This accounts for the fast initial recovery of $\mathrm{G}^{\prime}$. The latter process contains further structural rearrangements of nanofibers that occur over time, leading to a slow increase in $\mathrm{G}^{\prime}$.

We hypothesized that if the plastic deformation under shear strain was minimized, then efficient recovery of $G^{\prime}$ occurs because the shear-induced clusters retained the original nanostructures that could act as "nuclei" for the structural recovery [51]. Based on this idea, the stabilization of the physical network of GPG nanofibers was performed using genipin as a low-toxic chemical crosslinker (Figure 6). GPG1 hydrogels became more resistant to plastic deformation as shown by the increase in the linear viscoelastic regime as a function of strain (Figure 6e). The self-healing property of GPG1 is also improved after genipin crosslinking (Figure $6 \mathrm{~g}$ ). Note that $G^{\prime}$ and $G^{\prime \prime}$ values at $100 \%$ strain after genipin treatment are higher than those without chemical crosslinking (Figure 5a), showing that our hypothesis is reasonable. It needs to be taken into account, however, that moduli at $100 \%$ strain of genipin-treated gel were smaller than those of untreated gel in the strain sweep measurements (Figure 6d). These results indicate that the process leading to high strain is one of parameters that affects gel disruption. Alternatively, genipin treatment rather resulted in the impaired self-healing ability of GPG3 gel (Figure 6h). We speculate that some of the genipins were used for intramolecular crosslinking, but not intermolecular crosslinking-genipins crosslinked two amino groups in the KAAK motif of GPG3. Intramolecular crosslinking was suggested from the results of SDS-PAGE (Figure 6d), where the band for GPG3 appeared at a higher position than that of the 
original GPG3 (17,670 Da) [31]. The modification of GPG3 by genipin might destabilize the self-assembled structure and make the nanofiber prone to dissociate at high strain, which caused a low extent of structural recovery.

\section{Materials and Methods}

\subsection{Sample Preparation}

GPG1 and GPG3 were expressed and purified as previously reported [31]. They were stored as lyophilized powders at $-20{ }^{\circ} \mathrm{C}$ until use. To prepare hydrogels, polypeptide powders were dissolved in $10 \mathrm{w} / \mathrm{v} \%$ sucrose (Wako Pure Chemical Industries, Osaka, Japan) aqueous solutions at $4{ }^{\circ} \mathrm{C}$. Concentrations of the polypeptides were determined by measuring the absorbance at $280 \mathrm{~nm}$ using a Nanodrop $2000 \mathrm{UV}$-visible spectrometer (Thermo Fisher Scientific, Wilmington, DE, USA). Adequate amounts of $10 \mathrm{w} / \mathrm{v} \%$ sucrose aqueous solutions were added to adjust polypeptides' concentrations to $0.050 \mathrm{wt} \%$, $0.089 \mathrm{wt} \%, 0.158 \mathrm{wt} \%, 0.281 \mathrm{wt} \%, 0.500 \mathrm{wt} \%$, and $0.889 \mathrm{wt} \%$. They were then incubated for $1 \mathrm{~d}$ (GPG1) and up to $7 \mathrm{~d}$ (GPG3) at $37^{\circ} \mathrm{C}$.

\subsection{Rheological Measurements}

The rheological measurements were conducted using an Anton Paar MCR302 rheometer with a $1^{\circ}$ cone-and-plate configuration $(25 \mathrm{~mm}$ diameter) and a $0.048 \mathrm{~mm}$ gap. The experiments which were controlled using an integrated Peltier system were performed at $37^{\circ} \mathrm{C}$. A solvent trap cover was used to keep the sample hydrated. The sample was transferred to the stage using a micropipette for fluidic dispersion or a spatula for hydrogels. They were left to equilibrate for $1 \mathrm{~h}$ on the stage at $37^{\circ} \mathrm{C}$ before measurements.

\subsection{TEM}

TEM was performed using JEOL JEM-2100plus at an accelerating voltage of $200 \mathrm{kV}$. The samples were applied to a collodion-coated grid ( $\mathrm{Cu} 100 \mathrm{mesh}$ ), stained with potassium Eu-encapsulated Preyssler-type phosphotungstate (Fujifilm Wako Pure Chemical Corporation, Osaka, Japan), and the excess solution was wiped away using blotting paper.

\subsection{Genipin Treatment}

Hydrogels of GPG1 and GPG3 with $0.5 \mathrm{wt} \%$ polypeptide concentration were obtained after incubation at $37^{\circ} \mathrm{C}$ for $1 \mathrm{~d}$ and $7 \mathrm{~d}$, respectively. Genipin (Wako Pure Chemical Industries, Osaka, Japan) was dissolved in $10 \mathrm{w} / \mathrm{v} \%$ sucrose aqueous solution to final concentrations of $1 \mathrm{mM}$ and $2 \mathrm{mM}$. The genipin solution ( $1 \mathrm{mM}$ or $2 \mathrm{mM})$ was carefully added to the top of the GPG1 or GPG3 gel, in which the volume of genipin solution and the hydrogel was $1: 1$. They were then incubated at $37^{\circ} \mathrm{C}$ for one day, followed by the removal of supernatants, and further incubated at $37^{\circ} \mathrm{C}$ for an additional six days. These genipin-treated gels were subjected to SDS-PAGE analysis. The gels $(18 \mu \mathrm{L})$ were denatured by mixing sample buffers $(6 \mu \mathrm{L})$ containing SDS (Wako Pure Chemical Industries, Osaka, Japan) followed by incubation at $37^{\circ} \mathrm{C}$ for $30 \mathrm{~min}$. They were applied to the wells of a PAGE precast gel (e-PAGEL E-T 12.5 L, Atto Corporation, Tokyo, Japan) and electrophoresed at a constant current of $35 \mathrm{~mA}$.

\section{Conclusions}

In this paper, the formation of hydrogels composed of self-assembled nanofibers of double-hydrophobic elastin-like block polypeptides, GPG1 and GPG3, is demonstrated for the first time. The hydrogels are obtained at the low polypeptide concentation of $0.5 \mathrm{wt} \%$. GPG3 having a cell-adhesion sequence has slower kinetics in hydrogel formation than GPG1, while the storage moduli $\mathrm{G}^{\prime}$ of mature gels are similar between GPG1 and GPG3 gels. The power law between $\mathrm{G}^{\prime}$ and polypeptide concentration suggests that GPG gels consist of entangled semiflexible networks as found in biological gel systems. The GPG gels show thixotropic behavior in which reversible gel-sol transition occurs with low and high shear strain applications. The degree of recovery of $G^{\prime}$ upon removal of high strain 
is improved in GPG1 gel after genipin treatment, where intermolecular crosslinking is successful. In contrast, the recovery is hampered in GPG3 gel after genipin treatment, probably because of the intramolecular crosslinks that interfere with the self-assembly of GPG3 molecules. These findings would provide deeper insight into the structure-property relationships of the self-assembling polypeptides [52] and a better design strategy for hydrogels with desired viscoelastic properties.

Author Contributions: Conceptualization, Y.S. and A.S.-N.; methodology, Y.S. and A.S.-N.; validation, Y.S., J.N., C.O., and A.S.-N.; investigation, Y.S.; data curation, Y.S. and A.S.-N.; writing-original draft preparation, Y.S. and A.S.-N.; writing-review and editing, J.N. and C.O.; supervision, A.S.-N. and C.O.; project administration, A.S.-N.; funding acquisition, A.S.-N. All authors have read and agreed to the published version of the manuscript.

Funding: This research was funded by JSPS KAKENHI (19H04467 and 20K21907) and JST A-STEP (JPMJTS1624).

Institutional Review Board Statement: The study was approved by the Institutional Ethics Committee of Nagoya University (reference number 18-14, 19 October 2020).

Informed Consent Statement: Not applicable.

Data Availability Statement: Not applicable.

Acknowledgments: The authors thank Eriko Hayashi for protein purification and SDS-PAGE analysis. TEM observation was carried out in the High Voltage Electron Microscope Laboratory at Nagoya University.

Conflicts of Interest: The authors declare no conflict of interest. The funders had no role in the design of the study; in the collection, analyses, or interpretation of data; in the writing of the manuscript, or in the decision to publish the results.

\section{References}

1. Geckil, H.; Xu, F.; Zhang, X.; Moon, S.; Demirci, U. Engineering hydrogels as extracellular matrix mimics. Nanomedicine 2010, 5, 469-484. [CrossRef]

2. Van Vlierberghe, S.; Dubruel, P.; Schacht, E. Biopolymer-based hydrogels as scaffolds for tissue engineering applications: A review. Biomacromolecules 2011, 12, 1387-1408. [CrossRef]

3. Da Silva, K.; Kumar, P.; Choonara, Y.E.; du Toit, L.C.; Pillay, V. Three-dimensional printing of extracellular matrix (ECM)mimicking scaffolds: A critical review of the current ECM materials. J. Biomed. Mater. Res. Part A 2020, 108, $2324-2350$. [CrossRef]

4. Mithieux, S.M.; Weiss, A.S. Elastin. Adv. Protein Chem. 2005, 70, 437-461. [CrossRef]

5. Muiznieks, L.D.; Keeley, F.W. Molecular assembly and mechanical properties of the extracellular matrix: A fibrous protein perspective. Biochim. Biophys. Acta 2013, 1832, 866-875. [CrossRef]

6. Nettles, D.L.; Chilkoti, A.; Setton, L.A. Applications of elastin-like polypeptides in tissue engineering. Adv. Drug Deliv. Rev. 2010, 62, 1479-1485. [CrossRef] [PubMed]

7. Sugawara-Narutaki, A.; Le, D.H.T. Elastin-like polypeptides as building motifs toward designing functional nanobiomaterials. Mol. Syst. Des. Eng. 2019, 4, 545-565. [CrossRef]

8. Annabi, N.; Mithieux, S.M.; Zorlutuna, P.; Camci-Unal, G.; Weiss, A.S.; Khademhosseini, A. Engineered cell-laden human protein-based elastomer. Biomaterials 2013, 34, 5496-5505. [CrossRef] [PubMed]

9. Lee, S.; Sani, E.S.; Spencer, A.R.; Guan, Y.; Weiss, A.S.; Annabi, N. Human-recombinant-elastin-based bioinks for 3D bioprinting of vascularized soft tissues. Adv. Mater. 2020, 32, e2003915. [CrossRef] [PubMed]

10. Urry, D.W. Molecular machines: How motion and other functions of living organisms can result from reversible chemical changes. Angew. Chem. Int. Ed. 1993, 32, 819-841. [CrossRef]

11. McHale, M.K.; Setton, L.A.; Chilkoti, A. Synthesis and in vitro evaluation of enzymatically cross-linked elastin-like polypeptide gels for cartilaginous tissue repair. Tissue Eng. 2005, 11, 1768-1779. [CrossRef] [PubMed]

12. González de Torre, I.; Santos, M.; Quintanilla, L.; Testera, A.; Alonso, M.; Rodríguez-Cabello, J.C. Elastin-like recombinamer catalyst-free click gels: Characterization of poroelastic and intrinsic viscoelastic properties. Acta Biomater. 2014, 10, $2495-2505$. [CrossRef]

13. Madl, C.M.; Katz, L.M.; Heilshorn, S.C. Bio-orthogonally crosslinked, engineered protein hydrogels with tunable mechanics and biochemistry for cell encapsulation. Adv. Funct. Mater. 2016, 26, 3612-3620. [CrossRef] [PubMed] 
14. Ibáñez-Fonseca, A.; Santiago Maniega, S.; Gorbenko Del Blanco, D.; Catalán Bernardos, B.; Vega Castrillo, A.; Álvarez Barcia, Á.J.; Alonso, M.; Aguado, H.J.; Rodríguez-Cabello, J.C. Elastin-like recombinamer hydrogels for improved skeletal muscle healing through modulation of macrophage polarization. Front. Bioeng. Biotechnol. 2020, 8, 413. [CrossRef] [PubMed]

15. Contessotto, P.; Orbanić, D.; Da Costa, M.; Jin, C.; Owens, P.; Chantepie, S.; Chinello, C.; Newell, J.; Magni, F.; Papy-Garcia, D.; et al. Elastin-like recombinamers-based hydrogel modulates post-ischemic remodeling in a non-transmural myocardial infarction in sheep. Sci. Transl. Med. 2021, 13, eaaz5380. [CrossRef]

16. Marsico, G.; Jin, C.; Abbah, S.A.; Brauchle, E.M.; Thomas, D.; Rebelo, A.L.; Orbanić, D.; Chantepie, S.; Contessotto, P.; Papy-Garcia, D.; et al. Elastin-like hydrogel stimulates angiogenesis in a severe model of critical limb ischemia (CLI): An insight into the glyco-host response. Biomaterials 2021, 269, 120641. [CrossRef]

17. McDaniel, J.R.; Radford, D.C.; Chilkoti, A. A unified model for de novo design of elastin-like polypeptides with tunable inverse transition temperatures. Biomacromolecules 2013, 14, 2866-2872. [CrossRef]

18. Glassman, M.J.; Olsen, B.D. Arrested phase separation of elastin-like polypeptide solutions yields stiff, thermoresponsive gels. Biomacromolecules 2015, 16, 3762-3773. [CrossRef]

19. Cirulis, J.T.; Keeley, F.W. Viscoelastic properties and gelation of an elastin-like polypeptide. J. Rheol. 2009, 53, 1215. [CrossRef]

20. Roberts, S.; Harmon, T.S.; Schaal, J.L.; Miao, V.; Li, K.J.; Hunt, A.; Wen, Y.; Oas, T.G.; Collier, J.H.; Pappu, R.V.; et al. Injectable tissue integrating networks from recombinant polypeptides with tunable order. Nat. Mater. 2018, 17, 1154-1163. [CrossRef]

21. Misbah, M.H.; Quintanilla, L.; Alonso, M.; Rodríguez-Cabello, J.C. Evolution of amphiphilic elastin-like co-recombinamer morphologies from micelles to a lyotropic hydrogel. Polymer 2015, 81, 37-44. [CrossRef]

22. Nagapudi, K.; Brinkman, W.T.; Thomas, B.S.; Park, J.O.; Srinivasarao, M.; Wright, E.; Conticello, V.P.; Chaikof, E.L. Viscoelastic and mechanical behavior of recombinant protein elastomers. Biomaterials 2005, 26, 4695-4706. [CrossRef]

23. Haghpanah, J.S.; Yuvienco, C.; Roth, E.W.; Liang, A.; Tu, R.S.; Montclare, J.K. Supramolecular assembly and small molecule recognition by genetically engineered protein block polymers composed of two SADs. Mol. BioSyst. 2010, 6, 1662-1667. [CrossRef]

24. Mizuguchi, Y.; Mashimo, Y.; Mie, M.; Kobatake, E. Temperature-responsive multifunctional protein hydrogels with elastin-like polypeptides for 3-D angiogenesis. Biomacromolecules 2020, 21, 1126-1135. [CrossRef] [PubMed]

25. Dandu, R.; Von Cresce, A.; Briber, R.; Dowell, P.; Cappello, J.; Ghandehari, H. Silk-elastinlike protein polymer hydrogels: Influence of monomer sequence on physicochemical properties. Polymer 2009, 50, 366-374. [CrossRef]

26. Xia, X.-X.; Xu, Q.; Hu, X.; Qin, G.; Kaplan, D.L. Tunable self-assembly of genetically engineered silk-elastin-like protein polymers. Biomacromolecules 2011, 12, 3844-3850. [CrossRef]

27. Fernández-Colino, A.; Arias, F.J.; Alonso, M.; Rodríguez-Cabello, J.C. Self-organized ECM-mimetic model based on an amphiphilic multiblock silk-elastin-like corecombinamer with a concomitant dual physical gelation process. Biomacromolecules 2014, 15, 37813793. [CrossRef]

28. Shi, W.H.; Pathiranage, T.M.S.K.; Marciel, A.B. Rheological properties of engineered protein polymer networks. MRS Bull. 2020, 45, 1048-1054. [CrossRef]

29. Le, D.H.T.; Hanamura, R.; Pham, D.-H.; Kato, M.; Tirrell, D.A.; Okubo, T.; Sugawara-Narutaki, A. Self-assembly of elastin-mimetic double hydrophobic polypeptides. Biomacromolecules 2013, 14, 1028-1034. [CrossRef] [PubMed]

30. Sugawara-Narutaki, A.; Yasunaga, S.; Sugioka, Y.; Le, D.H.T.; Kitamura, I.; Nakamura, J.; Ohtsuki, C. Rheology of dispersions of high-aspect-ratio nanofibers assembled from elastin-like double-hydrophobic polypeptides. Int. J. Mol. Sci. 2019, 20, 6262 [CrossRef] [PubMed]

31. Le, D.H.T.; Tsutsui, Y.; Sugawara-Narutaki, A.; Yukawa, H.; Baba, Y.; Ohtsuki, C. Double-hydrophobic elastin-like polypeptides with added functional motifs: Self-assembly and cytocompatibility. J. Biomed. Mater. Res. Part A 2017, 105, 2475-2484. [CrossRef]

32. Tamburro, A.M.; Bochicchio, B.; Pepe, A. Dissection of human tropoelastin: Exon-by-exon chemical synthesis and related conformational studies. Biochemistry 2003, 42, 13347-13362. [CrossRef]

33. Le, D.H.T.; Okubo, T.; Sugawara-Narutaki, A. Beaded nanofibers assembled from double-hydrophobic elastin-like block polypeptides: Effects of trifluoroethanol. Biopolymers 2015, 103, 175-185. [CrossRef]

34. Hyun, K.; Kim, S.H.; Ahn, K.H.; Lee, S.J. Large amplitude oscillatory shear as a way to classify the complex fluids. J. Non-Newtonian Fluid Mech. 2002, 107, 51-65. [CrossRef]

35. Daniel, C.; Hamley, I.H.; Wilhelm, M.; Mingvanish, W. Non-linear rheology of a face-centred cubic phase in a diblock copolymer gel. Rheol. Acta 2001, 40, 39-48. [CrossRef]

36. Greenfield, M.A.; Hoffman, J.R.; de la Cruz, M.O.; Stupp, S.I. Tunable mechanics and peptide nanofiber gels. Langmuir 2010, 26, 3641-3647. [CrossRef]

37. Raeburn, J.; Mendoza-Cuenca, C.; Cattoz, B.N.; Little, M.A.; Terry, A.E.; Cardoso, A.Z.; Griffiths, P.C.; Adams, D.J. The effect of solvent choice on the gelation and final hydrogel properties of Fmoc-diphenylalanine. Soft Matter 2015, 11, 927-935. [CrossRef]

38. MacKintosh, F.C.; Käs, J.; Janmey, P.A. Elasticity of semiflexible biopolymer networks. Phys. Rev. Lett. 1995, 75, 4425-4428. [CrossRef]

39. Morse, D.C. Viscoelasticity of concentrated isotropic solutions of semiflexible polymers. 1. model and stress tensor. Macromolecules 1998, 31, 7030-7043. [CrossRef]

40. Palmer, A.; Mason, T.G.; Xu, J.; Kuo, S.C.; Wirtz, D. Diffusing wave spectroscopy microrheology of actin filament networks. Biophys. J. 1999, 76, 1063-1071. [CrossRef] 
41. Greth, C.; Roberts, W.W.; Ferry, J.D. Rheology of fibrin clots. II. Linear viscoelastic behavior in shear creep. Biophys. Chem. 1974, 2, 208-217. [CrossRef]

42. Schmidt, F.G.; Hinner, B.; Sackmann, E.; Tang, J.X. Viscoelastic properties of semiflexible filamentous bacteriophage fd. Phys. Rev. E 2000, 62, 5509-5517. [CrossRef]

43. Tacias-Pascacio, V.G.; García-Parra, E.; Vela-Gutiérrez, G.; Virgen-Ortiz, J.J.; Berenguer-Murcia, Á.; Alcántara, A.R.; FernandezLafuente, R. Genipin as an emergent tool in the design of biocatalysts: Mechanism of reaction and applications. Catalysts 2019, 9, 1035. [CrossRef]

44. Dimida, S.; Demitri, C.; De Benedictis, V.M.; Scalera, F.; Gervaso, F.; Sannino, A. Genipin-cross-linked chitosan-based hydrogels: Reaction kinetics and structure-related characteristics. J. Appl. Polym. Sci. 2015, 132, 42256. [CrossRef]

45. Baker, A.E.G.; Tam, R.Y.; Shoichet, M.S. Independently tuning the biochemical and mechanical properties of 3D hyaluronan-based hydrogels with oxime and diels-alder chemistry to culture breast cancer spheroids. Biomacromolecules 2017, 18, 4373-4384. [CrossRef]

46. Wychowaniec, J.K.; Smith, A.M.; Ligorio, C.; Mykhaylyk, O.O.; Miller, A.F.; Saiani, A. Role of sheet-edge interactions in $\beta$-sheet self-assembling peptide hydrogels. Biomacromolecules 2020, 21, 2285-2297. [CrossRef]

47. Yin, Z.; Wu, F.; Xing, T.; Yadavalli, V.K.; Kundu, S.C.; Lu, S. A silk fibroin hydrogel with reversible sol-gel transition. RSC Adv. 2017, 7, 24085-24096. [CrossRef]

48. Jacob, R.S.; Ghosh, D.; Singh, P.K.; Basu, S.K.; Jha, N.N.; Das, S.; Sukul, P.K.; Patil, S.; Sathaye, S.; Kumar, A.; et al. Self healing hydrogels composed of amyloid nano fibrils for cell culture and stem cell differentiation. Biomaterials 2015, 54, 97-105. [CrossRef] [PubMed]

49. Zanna, N.; Focaroli, S.; Merlettini, A.; Gentilucci, L.; Teti, G.; Falconi, M.; Tomasini, C. Thixotropic peptide-based physical hydrogels applied to three-dimensional cell culture. ACS Omega 2017, 2, 2374-2381. [CrossRef]

50. Gavel, P.K.; Kumar, N.; Parmar, H.S.; Das, A.K. Evaluation of a peptide-based coassembled nanofibrous and thixotropic hydrogel for dermal wound healing. ACS Appl. Biomater. 2020, 3, 3326-3336. [CrossRef]

51. Lin, Y.-J.; Chuang, W.-T.; Hsu, S. Gelation mechanism and structural dynamics of chitosan self-healing hydrogels by in situ SAXS and coherent X-ray scattering. ACS Macro Lett. 2019, 8, 1449-1455. [CrossRef]

52. Inaba, H.; Matsuura, K. Peptide nanomaterials designed from natural supramolecular systems. Chem. Rec. 2019, 19, 843-858. [CrossRef] 